\title{
Çukurova Üniversitesi Tıp Fakültesi Adli Tıp Anabilim Dalına 2019-2020 Yıllarında Yaş Tayini İçin Başvuran Mülteci Olguların Değerlendirilmesi
}

\section{Evaluation of Refugee Cases Applied for Age Estimation Between 2019-2020 In The Department of Forensic Medicine, Cukurova University Medical Faculty}

\author{
Kenan KAYA ${ }^{1}(\mathbb{D})$, Sıla ASLAN ${ }^{2}(\mathbb{D})$, Toygün Anıl ÖZESEN ${ }^{1}(\mathbb{D})$, Mete Korkut GÜLMEN ${ }^{1}$ (D)
}

\author{
1 Çukurova Üniversitesi, Tıp Fakültesi , Adli Tıp Anabilim Dalı, Adana,TÜRKIYE \\ 2 Hatay Devlet Hastanesi, Adli Tıp Birimi, Hatay,TÜRKIYE
}

Öz.

Amaç: Yaş tayini, Adli Tıp alanının önemli konularından biridir. Hukukta yargılamanın işleyişi ve sonuçlandırılması açısından bireyin yaşı belirleyicidir. Yaş tayini yapmak için en sık kullanılan yöntem radyolojik olarak kemik yaşı tayinidir. Yaş tayini değerlendirmeleri; hukuki açıdan kişilerin cezai sorumlulukları olup olmadığı, hukuki hakları veya suçtan zarar görene göre yargı sistemi tarafından verilecek hükmü belirlemek amacıyla istenmektedir.

Materyal ve Metod: Çalışmamızda, Çukurova Üniversitesi Tıp Fakültesi Adli Tıp Anabilim Dalı polikliniğimize 2019-2020 yılları arasında ilgili adli makamlar tarafından yaş tayini istemiyle yönlendirilen 81 mülteci olgunun kimlik yaşı, evlendiklerini belirttikleri yaş, çocuk sahibi olup olmadıkları, yaş tayini istenme nedeni incelendi. Tüm olguların radyolojik kemik yaşları Greulich-Pyle ve Gilsanz-Ratib Atlaslarına göre değerlendirilmiştir.

Bulgular: Çalışma süresinde 74'ü kadın ve 7'si erkek olmak üzere 81yaş tayini istemi yapılmıştır. 2 olguda gebelik nedeniyle yaş tayini değerlendirilmesi yapılamamıştır. 53 olgunun nüfus kayıtları ile kemik yaşlarının uyumlu olduğu görülmüştür. Nüfus kayıtları ve kemik yaşları arasında fark olduğu tespit edilen olguların 8 'inin nüfus kaydından küçük, $18^{\prime}$ inin nüfus kaydından büyük olduğu görülmüştür. Olguların yaş tayini için yönlendirme nedenleri değerlendirildiğinde kadınların tamamında, erkeklerin çoğunda $(\% 85,7)$ cinsel istismar nedeniyle yaş tayini istendiği görüldü.

Sonuç: Çalışmamızda değerlendirilen olguların neredeyse tamamının yasal evlenme yaşının altında çocuklar olması mülteciler arasında çocuk istismarının geldiği endişe verici noktayı göstermektedir. Çocuk yaş evlilikleri ve dolayısıyla çocuk istismarının önlenmesi, konuyla ilgili farkındalığın artırılması ve halk sağlığı açısından bu çocukların izlenmesi sağlanmalıdır.

Anahtar Kelimeler: Mülteci, Kemik yaşı, Cinsel istismar, Çocuk evlilikleri

\section{Abstract}

Background: Age estimation is one of the important issues in the field of Forensic Medicine. The age of the individual is decisive in terms of the functioning and conclusion of the legal proceedings. The most common method for age estimation is radiological estimation of bone age. Age estimation assessments are requested to determine whether individuals legally have criminal responsibilities or not, legal rights of individuals, or the verdict to be given by the judicial system according to the person who has been harmed by the crime. Materials and Methods: In our study; information about identity age, the age at which they say they were married, whether they have children, the reason for requesting age estimation of 81 refugee cases, who were referred to our outpatient clinic of Çukurova University Faculty of Medicine, Department of Forensic Medicine between 2019-2020 with the request of age estimation by the relevant judicial authorities, was examined. Radiological bone ages of all cases were evaluated according to Greulich-Pyle and Gilsanz-Ratib Atlas.

Results: Age estimation of 81 cases, including 74 female and 7 male cases, was conducted in this study. Age estimation could not be evaluated in 2 cases due to pregnancy. It was observed that the registration records of 53 cases were compatible with bone ages. It was observed that 8 of the cases were younger and 18 of the cases were older than the recorded age at register. When the reasons for referral for age estimation of the cases were evaluated; It was observed that all women and most men (85.7\%) asked for age estimation due to sexual abuse.

Conclusions: e fact that almost all of the cases evaluated in our study were children under the legal age of marriage, shows the alarming point of child abuse among refugees. Childhood marriages and related child abuse should be prevented, awareness about this topic should be increased and these children should be monitored in terms of public health.

Keywords: Refugee, Bone age, Sexual abuse, Childhood marriages
Sorumlu Yazar / Corresponding Author

\section{Dr. Toygün Anıl ÖZESEN}

Çukurova Üniversitesi Tıp Fakültesi

Balcalı Hastanesi, Adli Tıp Anabilim Dalı, Adana/TÜRKIYE

E-mail: toygunanilozesen@gmail.com

Geliş tarihi / Received: 13.08.2021

Kabul tarihi / Accepted: 16.11.2021

DOI: 10.35440/hutfd.982364 


\section{Giriş}

Birleşmiş Milletler (BM) Mültecilerin Hukuki Statüsüne ilişkin 1951 Sözleşmesi'ne göre mülteci tanımı; 'ırkı, dini, milliyeti, belli bir sosyal gruba mensubiyeti veya siyasi düşünceleri nedeniyle zulüm göreceği konusunda haklı bir korku taşıyan ve bu yüzden ülkesinden ayrılan ve korkusu nedeniyle geri dönemeyen veya dönmek istemeyen kişi" olarak yapılmaktadır (1).

Her yıl dünyanın her yerinden binlerce insan kendi ülkelerindeki çatışmalardan, felaketlerden ve şiddetten kaçmak, uluslararası sınırları geçmek için evlerinden kaçmaktadır. Bu insani acil durumlarda, mülteciler ve ülke içinde yerinden edilmiş kişilerin, sağlıklarını etkileyen büyük bir baskıya maruz kaldıkları görülmektedir. Dünya'nın şu anda artan sayıda mülteci ile, İkinci Dünya Savaşı'ndan bu yana en büyük göç krizini yaşadığı öne sürülmektedir.

Cinsel şiddet, cinsel bir eylem veya mağdurun gönüllü rızası olmadan veya rıza gösteremeyecek veya reddedemeyecek biriyle cinsel bir eylem gerçekleştirme girişimi olarak tanımlanmakta, zorla yerinden edilme ve iltica sırasında mevcut bir tehdit olarak kabul edilmektedir $(2,3)$.

Savaş zamanlarında, kadınlar ve kız çocukları cinsel şiddete karşı daha savunmasızdır ve erken yaşta veya zorla evlilik, eş istismarı, çocuk cinsel istismarı ve insan ticareti gibi şiddet biçimleri açısından daha büyük risk altındadır (3). Çocuk istismarının dünya üzerinde görülen en yaygın şekillerinden biri de çocukluk dönemindeki evliliklerdir. Reşit olunmayan evliliklerin oranı dünyada düşmekle beraber, Türkiye gibi yoğun göç alan ülkelerde varlığını sürdürmektedir (4). Çocukluk dönemindeki evlilikler, 18 yaşını doldurmamış, bedensel, fizyolojik ve mental açıdan evlenmek ve çocuk sahibi olmak gibi yükümlülükleri taşımaya hazır olmayan çocuğun dahil olduğu evlilik olarak tanımlanmaktadır (5).

Kanun koyucu, Türk Ceza Kanunu madde 103'te yaş gruplarına göre bir ayrıma giderek 15 yaşını doldurmamış veya doldurmasına rağmen fiilin hukuki anlam ve sonuçlarını algılayamayan çocuklara karşı gerçekleştirilen her tür cinsel içerikli davranışı istismar sayarken, 15 yaşından büyük çocuklara sadece cebir, tehdit, hile veya iradeyi etkileyen başka bir nedenden dolayı gerçekleştirilen cinsel içerikli davranışları cinsel istismar kabul etmiştir (6). Kanun metninden de anlaşılacağı üzere, mağdurun 15 yaşından küçük olması halinde rızasının olamayacağı kabul edilmekte, bu durum kanuni bir karine sayılmaktadır. Bu durumlarda algılama yeteneği ile ilgili olarak araştırmaya gerek görülmemektedir (7). Ülkemizde geçmiş yıllara göre oldukça azalmış olmakla birlikte doğum kayıtlarının gerçeğe uygun yapılmadığı durumlar göz önüne alındığında, yaşın gerçeğe uygun olarak tespiti ile ilgili de bazı sorunlar bulunmaktadır. Bu nedenle kanun düzenlemesinde çocuğun yaşı esas alındığından, yaş kayıtlarına sıklıkla itiraz edilmektedir.

Adli yaş çalışmaları çoğu ülkede; medeni hukuk, ceza hukuku ve iltica davalarında kişilerin 14-22 yaşlarını belirle mek amacıyla, emeklilik veya yaşlıık aylığı hak edilme durumlarında ise 60 veya 65 yaşında olup olmadıklarının belirlenebilmesi amacıyla gerçekleştirilmektedir (8).

Yaş tayini açısından özellikle adölesan yaşlarda değerlendirme yapılırken; boy ve ağırlık gibi bulguların yanında vücudun büyüme ve gelişmesine eşlik eden ikincil cinsiyet karakterlerinin, percentil endekslerinin, radyolojik inceleme ile vücut kemiklerinin epifiz hatlarının değerlendirmeye alınması gerekmektedir. İleri yaşlarda ise kemiklerde meydana gelen kalsifikasyonlar ve genel olarak kemiklerin yıpranma durumuna göre değerlendirme yapılmaktadır.

Son yıllarda yaşanan göç dalgası ile birlikte özellikle bölgemizde artan göçmen yoğunluğu sonrası, hem kimlik düzenlenmesinde doğum tarihleri ile ilgili meydana gelen kayıt yanlışlıkları hem de kültürel veya başka sebeplerle çocuk yaşta gerçekleştirilen evlilikler nedeniyle tarafımıza yaş tayini için gönderilen olgu sayısında artış olduğu görülmüştür. Bu nedenle Adli Tıp Anabilim Dalımıza 2019-2020 yılları arasında adli makamlarca yaş tayini için yönlendirilmiş 81 olguya ait raporlar retrospektif olarak incelenerek elde edilen verilerin literatüre kazandırılması amaçlanmıştır.

\section{Materyal ve Metod}

Çalışmamızda; Anabilim dalımıza 2019-2020 yılları arasında ilgili adli makamlar tarafından kemik yaşı tayini istemiyle yönlendirilen ve raporları düzenlenen 81 mülteci olgu retrospektif olarak incelenmiştir.

Çalışmamız için 22 Ocak 2021 tarih ve 107 Sayılı T.C. Çukurova Üniversitesi Tıp Fakültesi Girişimsel Olmayan Klinik Araştırmalar Etik Kurulu Toplantısında Etik Yönden Uygun olduğuna dair 9 Karar Numarası ile onay alınmıştır.

Veriler kayıt altına alınırken; cinsiyet, kimlik yaşı, evlendikleri belirtilen yaş, çocuk sahibi olup olmadığı, yaş tayini istenme sebepleri, hangi yaşta olduklarının iddia edildiği, tespit edilen kemik yaşları değerlendirme kriterleri olarak seçilmiştir. Kemik yaşları tayin edilmek üzere sol el-el bilek, sol dirsek, sol omuz ve pelvis grafileri çekilerek, ilgili kemiklerin epifiz hatlarının mevcut halleri Greulich-Pyle ve Gilsanz-Ratib kemik yaşı Atlasları ile karşılaştırılarak değerlendirmede bulunulmuştur $(9,10)$.

\section{istatistik Analiz}

İstatistiksel analizler için SPSS Versiyon 20 kullanıldı. Üzerinde durulan özelliklerden kategorik değişkenler frekans ve yüzde olarak ifade edilmiştir.

\section{Bulgular}

Çalışmamızda; Anabilim dalımıza 2019-2020 yılları arasında ilgili adli makamlar tarafından yaş tayini istemiyle yönlendirilen ve rapor düzenlenen 81 mülteci olgunun radyolojik kemik yaşları Greulich-Pyle ve Gilsanz-Ratib Atlaslarının her ikisine göre değerlendirilmiş, değerlendirmede atlaslar arası fark tespit edilmemiştir. 
Çalışmamızda; 81 mülteci olgunun 74'ünün kadın, 7'sinin erkek olduğu, başvuruların kimlik yaşına göre inceleme yapıldığında, en küçük yaş 10, en büyük yaşın 19 olduğu görüldü.

Çalışmamızda; olguların kendi yaşları konusunda görüşleri değerlendirildiğinde, 54 olgunun kimlik yaşlarından daha büyük olduklarını, 8 olgunun küçük olduklarını, 19 olgunun kimlik yaşlarının doğru olduğunu iddia ettiği görüldü. İddia edilen yaş ve kimlik yaşları arasındaki farkların cinsiyetlere göre dağılımı Tablo 1'de gösterilmektedir.

Çalışmamızda; 2 olguda gebelik nedeniyle yaş tayini çalışmaları yapılamamış olup, 18 olgunun kemik yaşının kimlik yaşından daha büyük olduğu, 8 olgunun kemik yaşının kimlik yaşından daha küçük olduğu,53 olgunun ise kemik ve kimlik yaşlarının birbiriyle uyumlu olduğu tespit edilmiştir. Çekilen grafilere göre tespit edilen kemik yaşı ile kimlik yaşları arasındaki farkların dağılımı Tablo 2'de gösterilmektedir.

Tablo 1. Kişilerin iddia ettikleri yaşları ile kimlik yaşları arasındaki yaş farkı ve cinsiyet dağılımı tablosu

\begin{tabular}{lcccccc}
\hline İddia Edilen Yaş ve Kimlik Yaşı Ara- & \multicolumn{2}{c}{ Kadın } & \multicolumn{2}{c}{ Erkek } & \multicolumn{2}{c}{ Toplam } \\
\cline { 2 - 7 } sındaki Fark & $\mathbf{n}$ & $\mathbf{\%}$ & $\mathbf{n}$ & $\mathbf{\%}$ & $\mathbf{n}$ & $\mathbf{\%}$ \\
\hline Kimlik Yaşından 2 Yaş Küçük & 2 & $\% 2,46$ & 5 & $\% 6,17$ & 7 & $\% 8,64$ \\
Kimlik Yaşından 1 Yaş Küçük & 1 & $\% 1,23$ & 0 & - & 1 & $\% 1,23$ \\
Kimlik Yaşı ile Aynı & 19 & $\% 23,45$ & 0 & - & 19 & $\% 23,45$ \\
Kimlik Yaşından 1 Yaş Büyük & 18 & $\% 22,22$ & 1 & $\% 1,23$ & 19 & $\% 23,45$ \\
Kimlik Yaşından 2 Yaş Büyük & 24 & $\% 29,62$ & 1 & $\% 1,23$ & 25 & $\% 30,86$ \\
Kimlik Yaşından 3 Yaş Büyük & 8 & $\% 9,87$ & 0 & - & 8 & $\% 9,87$ \\
Kimlik Yaşından 4 Yaş Büyük & 2 & $\% 2,46$ & 0 & - & 2 & $\% 2,46$ \\
Toplam & 74 & $\% 91,35$ & 7 & $\% 8,64$ & 81 & $\% 99,99$ \\
\hline
\end{tabular}

*Tabloda kişilerin iddia ettikleri yaşları ile kimlik yaşları arasındaki yaş farkı gösterilmekte olup yüzdeler hesaplanırken virgül sonrası ilk iki hane alındığından yüzdeler toplamı farklılık göstermektedir

Tablo 2. Kimlik yaşı ve tespit edilen kemik yaşlarının karşılaştırma tablosu

\begin{tabular}{lccc}
\hline Kimlik Yaşı ile Kemik Yaş Farkı & Olgu Sayısı (n) & Oran (\%) \\
\cline { 1 - 2 } Kimlik Yaşından 3 Yaş Küçük & 2 & $\% 2,53$ \\
Kimlik Yaşından 2 Yaş Küçük & 3 & $\% 3,79$ \\
Kimlik Yaşından 1 Yaş Küçük & 53 & $\% 3,79$ \\
Kimlik Yaşından 1 Yaş Büyük & 16 & $\% 67,08$ \\
Kimlik Yaşından 2 Yaş Büyük & 1 & $\% 20,25$ \\
Kimlik Yaşından 3 Yaş Büyük & 1 & $\% 1,26$ \\
Toplam & 79 & $\% 99,26$ \\
\hline
\end{tabular}

*2 olgunun gebe olması nedeniyle kemik grafileri çekilemediğinden değerlendirme yapılamamıştır. Bu nedenle 79 olguya göre yüzde hesaplaması yapılmış olup yüzdeler hesaplanırken virgül sonrası ilk iki hane alındığından yüzdeler toplamı farklılık göstermektedir.

Çalışmamızda; 74 kadın olgunun gebelik durumlarına göre inceleme yapıldığında; en az bir kez doğum yapan 64 olgu olduğu, 10 olgunun doğum yapmamış olduğu, 52 olgunun 12 aydan küçük, 5 olgunun 12-24 ay arasında, 7 olgunun 24 aydan daha büyük çocuk sahibi olduğu tespit edilmiştir. Olguların çocuk sahiplik durumu ve çocukların yaş dağılımı Tablo 3'te gösterilmektedir.
Çalışmamızda; olguların yaş tayini için gönderilme nedenleri incelendiğinde kadın olguların tamamının, erkek olguların ise büyük bir çoğunluğunun $(\% 85,7)$ cinsel istismar nedeniyle tarafımıza gönderilmiş olduğu, 74 kadın olgunun 71 'inin $(\% 95,9)$ evli olduğunu (imam nikahı) beyan ettiği tespit edilmiştir. Olguların adli makamlarca yaş tayini için gönderilme nedenleri, cinsiyetleri ve evlilik durumlarının dağılımı Tablo 4'te gösterilmektedir.

Tablo 3. Çocuk sahibi olma durumu ve çocukların yaşlarının dağılımı tablosu

\begin{tabular}{lcc}
\hline Doğum yapma ve doğan çocuk yaşları & Olgu Sayısı(n) & Oran (\%) \\
\hline Çocuk sahibi olmayan & 10 & $\% 13,51$ \\
Çocuk 0-12 ay & 52 & $\% 70,27$ \\
Çocuk 12-24 ay & 5 & $\% 6,75$ \\
Çocuk 24 ay ve daha büyük & 7 & $\% 9,45$ \\
Toplam & 74 & $\% 99,9$ \\
\hline
\end{tabular}

* Kadın cinsiyette olgu sayısının 74 olması nedeniyle yüzde hesaplaması bu sayıya göre yapılmış olup yüzdeler hesaplanırken virgül sonrası ilk iki hane alındığından yüzdeler toplamı farklılık göstermektedir. 
Tablo 4. Adli makamlarca yaş tayini amacıyla gönderilen olguların gönderilme nedenleri, cinsiyetleri ve beyan ettikleri evlilik (imam nikahı) durumları tablosu

\begin{tabular}{|c|c|c|c|c|c|c|c|c|}
\hline \multicolumn{9}{|c|}{ Yaş tayini Amacıyla Gönderilme Nedeni } \\
\hline \multirow[t]{3}{*}{ Cinsiyet } & \multicolumn{4}{|c|}{ Cinsel İstismar } & \multicolumn{2}{|c|}{ Kayıt Hatası } & \multicolumn{2}{|c|}{ Toplam } \\
\hline & \multicolumn{2}{|c|}{ Cinsel Saldırı } & \multicolumn{2}{|c|}{ Evlilik } & \multirow[b]{2}{*}{$\mathrm{n}$} & \multirow[b]{2}{*}{$\%$} & \multirow[b]{2}{*}{$\mathrm{n}$} & \multirow[b]{2}{*}{$\%$} \\
\hline & $\mathrm{n}$ & $\%$ & $\mathrm{n}$ & $\%$ & & & & \\
\hline Kadın & 3 & $\% 3,70$ & 71 & $\% 87,65$ & 0 & - & 74 & $\% 91,35$ \\
\hline Erkek & 6 & $\% 7,40$ & 0 & - & 1 & $\% 1,23$ & 7 & $\% 8,64$ \\
\hline Toplam & 9 & $\% 11,1$ & 71 & $\% 87,65$ & 1 & $\% 1,23$ & 81 & $\% 99,9$ \\
\hline
\end{tabular}

* Yüzdeler hesaplanırken virgül sonrası ilk iki hane alındığından yüzdeler toplamı farklılık göstermektedir.

\section{Tartışma}

Adli amaçlarla yaş tayini; kişilerin hukuki ehliyetleri ve ceza sorumluluklarının değerlendirilebilmesi, kimlik yaşlarının küçük olması durumunda işe girme, 18 yaş altında evlilik, spor müsabakalarına katılım, askere alınma gibi birçok durumda adli makamlarca veya kişilerin bireysel başvuruları ile gerçekleştirilmektedir (11-13).

Son yıllarda dünya dinamiklerinde meydana gelen değişliklerin neden olduğu savaşlar-çatışmalar-karışıklıklar neticesinde artan sığınmacı sayılarının beraberinde getirdiği olumsuzluklar arasında cinsel şiddet olgularının artışının da olduğu belirtilmektedir $(14,15)$. Ülkemiz ve özellikle bölgemizin bu göç dalgasının içerisinde kalması nedeniyle güncel çaış̧ma alanımız içerisinde bu olgularla karşılaşma sıklığımızın artmış olduğu görülmektedir. Çalışmamızı gerçekleştirdiğimiz Adana ilinin mülteci sayısı açısından Türkiye'de 5. sırada olması (16), yabancı uyruklu vaka oranının yüksek olmasını açıklamaktadır.

Adli makamlarca tarafımıza gönderilen mülteci olguların çok büyük kısmında 15 yaş altı evlilik, 15 yaş altı doğum veya kimlik yaşına göre 15 yaş altında cinsel ilişkiye bağlı doğum nedeniyle açılan kamu davalarında kişilerin yaşlarına ilişkin rapor düzenlenmesi istenmektedir. Türk Ceza Kanunun Madde 103'te 15 yaşını doldurmamış veya doldurmasına rağmen fiilin hukuki anlam ve sonuçlarını algılayamayan çocuklara karşı gerçekleştirilen her tür cinsel içerikli davranışın istismar olarak kabul edilmesi (5) nedeniyle, resmi olmayan evlilik nedeniyle tarafımıza gönderilen olgular, cinsel istismar olguları olarak değerlendirmeye alınmış olup çalışmamızda; olguların başvuru nedenleri değerlendirildiğinde kadınların tamamında, erkeklerin çoğunda $(\% 85,7)$ cinsel istismar nedeniyle yaş tayini istendiği görülmüştür. TUiK verileri kapsamında İçişleri Bakanlığı tarafından hazırlanan "Yabancı Uyruklu Çocuklara Yönelik Cinsel Suç Atlası" isimli raporda, ülkemizde mevcut refakatsiz sığınmacı çocukların \%84'ünün 15 yaşın altında olduğu; bu çocuklardan cinsel istismara maruz kalanların 2014 yılı 170 kişi, 2017 yılında 1421 kişi olduğu belirtilmiştir (15). 2011 yılı cinsel istismar mağduru olan çocuklar ile yapılan bir çalışmada, yabancı uyruklu olma oranının \%5 olduğu saptanmıştır (17). Muğla'da 240 cinsel istismar vakasının \%2,9'unun yabancı uyruklu olduğu saptanmış$\operatorname{tir}(18)$.

Çalışmamızda; olguların 74'ünün (\%91,3) kadın, 7'sinin $(\% 8,6)$ erkek olduğu; kimlik yaşına göre en küçük yaşın 10 , en büyük yaşın 19 olduğu görülmüştür. Türkiye'de kız çocuklarının 18 yaşından önce yaklaşık \%15'inin, 15 yaşından önce ise \%1'inin evlendiği tahmin edilmektedir ve bu oranlar da Avrupa'nın en yüksek çocuk evlilik oranlarından biridir (5). UNICEF tarafından 2016 yılında yayınlanan rapora göre; 28 milyon çocuğun mevcut savaş nedenli güvenlik, sağlık ve ekonomik problemler ile ülkelerinden ayrılmak zorunda olduğu; dünyadaki her 200 çocuktan 1 'inin ve doğdukları ülkenin dışında yaşayan her 3 çocuktan 1'inin mülteci olduğu belirtilmekte; Türkiye'nin yaşa göre gruplandırılmış veriler olmasa da dünyada en çok sayıda çocuk mülteciye ev sahipliği yaptığı düşünülmektedir (19).

Çalışmamızda, olguların kendi yaşları konusunda görüşleri alındığında; 54 olgunun kimlik yaşlarından daha büyük olduklarını, 8 olgunun küçük olduklarını, 19 olgunun kimlik yaşlarının doğru olduğunu belirttikleri görüldü. Kimlik yaşlarından daha büyük olduğunu iddia eden olguların sayısının daha yüksek olmasının, istismarı örtbas etmek için evlenme/evlendirilme ve çeşitli toplumsal baskılar nedeniyle olduğu düşünülmektedir.

Çalışmamızda; 2 olguda gebelik nedeniyle yaş tayini çalışmaları yapılamamış olup (Belirtilen yüzdelik değerler, değerlendirilemeyen 2 olgunun toplam olgu sayısından çıkarılması sonrası kalan 79 olguya göre hesaplanmıştır.), 18 (\%22,78) olgunun kemik yaşının kimlik yaşından daha büyük olduğu, 8 $(\% 10,12)$ olgunun kemik yaşının kimlik yaşından daha küçük olduğu, 53 (\%67) olgunun ise kemik ve kimlik yaşlarının birbiriyle uyumlu olduğu tespit edilmiştir. 2011 yılında Tokat bölgesinde yapılan bir çalışmada, yaş tayini nedeni ile başvuran olguların \%89.2'sinin değerlendirme sonucunda tespit edilen yaş ile nüfusa kayıtlı olduğu yaş arasında fark olduğu, olguların \%75,7'sinin değerlendirme sonucunda kemik yaşının nüfusa kayıtlı olduğu yaştan daha büyük bulunduğu bildirilmiştir (11). Çalışmalar arasındaki farklılığın zamana, toplumsal dinamiklere ve göç dalgasına bağlı olduğu düşünülmektedir.

Çalışmamızda, en az bir kez doğum yapan 64 olgu olduğu saptanmıştır. Mülteci kamplarındaki tüm çocukların cinsel istismar ve insan ticaretine karşı savunmasız oldukları, kız çocuklarının zorla cinsel ilişkiye ve erken çocuk doğurmaya maruz kalmanın yanı sıra aile çevrelerindeki cinsiyet rolleriyle ilişkili olarak artan risk alma deneyimi yaşadıkları bildirilmektedir $(20,21)$. Aile planlaması dahil olmak üzere cinsel sağlık 
ve üreme sağlığı hizmetleri ile ürünlerinin kullanımı ve bilgisinin de insani yardım ortamlarındaki kadınlar ve çocuklar arasında genellikle düşük olduğu bildirilmektedir (22).

Çalışmamızda değerlendirilen olguların neredeyse tamamının Türkiye Cumhuriyeti Kanunlarına göre yasal evlenme yaşının altında olması mülteciler arasında çocuk istismarının geldiği endişe verici noktayı göstermektedir. Suriye Kişisel Statü Kanununa göre, evlilik yaşı erkek çocukta asgari 18 yaş, kız çocukta ise 17 yaş olarak belirlenmiş olmakla birlikte 15 yaşını dolduran bir erkek çocuğu veya 13 yaşını dolduran bir kız çocuğu büluğ çağına girdiğini iddia ediyorsa, hakimin bu iddianın samimiyetine inanması ve kişilerin yeterli fiziki olgunluk derecelerine eriştiği konusunda kanaate vardığı takdirde erkek veya kız çocuğunun evlenmelerine izin verebilmektedir (23). Türkiye Cumhuriyeti ve Suriye ülkeleri arasındaki evlilik yaşına ilişkin bu farklılık nedeniyle kişilerin ülkelerinde gerçekleştirdikleri evlilikler göç ettikleri ülkelerde geçerliliğini kaybetmekte ve bizimde günlük adli tıp pratiğinde oldukça fazla bu olgularla karşılaşmamıza neden olmaktadır. Ayrıca hukuksal düzenlemeler o toplumun sosyal yapısıyla bağdaşmaları ve yaşama şekliyle ilişkili olmalarından dolayı, toplulukların küçük yaşta evliliklere karşı hassasiyetleri daha düşük seviyede olmakta, doğal sayılmaktadır. Bu nedenlerle hem göç etmenin getirmiş olduğu sosyal zorluklarla baş etme yöntemi olarak evliliğin sunulması hem de göç edilen yerlerde mevcut kanunların tam olarak bilinmemesi ile evlilikler meydana gelmektedir.

Savaşın yıkıcı etkileri ve travmatik süreçlerine maruziyeti tespit edilerek mülteci çocuklara ve onların ailelerine psikososyal açıdan destek hizmetleri sunulmalı, rehabilitasyon ve koruma programlar geliştirilmelidir. Bütüncül sağlık hizmetlerinin erişiminin etkin sağlanabilmesi, aile fertlerinin tekrar bir araya gelebilmeleri desteklenmeli ve isteyenlere Türkçe öğrenimi konusunda fırsatlar yaratılmalıdır. Entegrasyon ve asimilasyon kavramları arasında karmaşıklıktan kaçınılarak gerekli önlemler alınmalı; mültecilerin kültürlerine, hayat tarzlarına ve ritüellerine saygı çerçevesinde çocuk merkezli eğitim programları hazırlanmalıdır. Çocuk evlilikleri, travmatik yaşantılar, sağlık, çocukların eğitim alamama, devam edememe, yoksulluk, çocuk işçiliği, dil problemi, uyum gibi temel konularda ortak hareket edilmeli ve verilen hizmetler takip edilmelidir (24).

Tüm dünyada $15-19$ yaş arası kadınların \%18'inin evli olduğu, 20-24 yaş arası kadınların \%21'inin 18 yaşından önce doğum yaptığı belirtilmektedir (25). Erken yaşta evliliklerin \%29 oran ile en sık Güney Asya'da, \%7 oran ile an az Orta ve Doğu Avrupa'da olduğu belirtilmektedir (25). Erken yaşta, bireylerin biyopsikososyal gelişimlerinin tam olarak gerçekleştirmeden yaptıkları evlilikler birçok sorunu beraberlerinde getirmektedirler. Bu evliliklerde çoğunlukla erken yaşta gebelik meydana gelmekte ve tıbbi açıdan adölesan yaş gebelikleri riskli gebelikler olarak değerlendirilmektedir (26). Ayrıca bu olgularda doğurganlık süresinin uzadığı ve daha fazla doğum gerçekleştiği belirlenmiştir (27).

Sonuç olarak çalışmamızda yaş tayini için tarafımıza yönlen- dirilen mülteci olguların çok büyük kısmının erken yaşta evlilik, gebelik veya cinsel istismara uğramış oldukları tespit edilmiş olup, erken yaşta evliliklerin ve dolayısıyla çocuk istismarının önlenmesi, konuyla ilgili farkındalığın artırılması ve halk sağlığı açısından izlenmesi sağlanmalıdır. Ayrıca yaş tayinine ilişkin düzenlenen raporların yargı sisteminde hükme direk etkili olması nedeniyle, değerlendirme yapılırken hata payını en aza indirgemek için mevcut ise yerel atlaslardan mevcut değil ise uluslararası alanda kabul görmüş atlaslar kullanılmalıdır.

Etik onam: Çalışmamı için 22 Ocak 2021 tarih ve 107 Sayılı T.C. Çuku-rova Üniversitesi Tıp Fakültesi Girişimsel Olmayan Klinik Araştırmalar Etik Kurulu Toplantısında Etik Yönden Uygun olduğuna dair 9 Karar Numarası ile onay alınmıştır.

\section{Yazar Katkıları:}

Konsept: K.K., T.Ö.

Literatür Tarama: S.A., T.Ö.

Tasarım: M.G., S.A.

Veri toplama: K.K., S.A., T.Ö.

Analiz ve yorum: M.G.

Makale yazımı: T.Ö., S.A.

Eleştirel incelenmesi: K.K., M.G.

Çıkar Çatışması: Yok

Finansal Destek: Yok

\section{Kaynaklar}

1. Jackson IC. The 1951 Convention Relating to the Status of Refugees: A universal basis for protection. Int'I J Refugee L. 1991;3:403.

2. Basile KC, Smith SG, Breiding $M$, Black MC, Mahendra RR. Sexual violence surveillance: Uniform definitions and recommended data elements. Version 2.0. 2014.

3. Ward J, Vann B. Gender-based violence in refugee settings. The Lancet. 2002;360:13-4.

4. Bilginer Ç, Kütük MÖ. Çocuk Evlilikleri. Turkiye Klinikleri J Child Psychiatry-Special Topics. 2017;3(3):188-94.

5. Çavlin A. Syrian Refugees in Turkey: A Demographic Profile and Linked Social Challenges: Routledge; 2020.

6. Celbis O, Ozdemir B, Kaya A. Examination of the sexually assaulted child/Cinsel saldiriya ugramis cocugun muayenesi. Turkish Pediatrics Archive. 2011:104-11.

7. Aslan S. Akut Cinsel İstismar ve Saldırı Olgularında Güncel Teknoloji ve Laboratuvar Kullanımı ile Raporlandırma Standardizasyonu Çalışması [Tıpta Uzmanlık Tezi]: Çukurova Üniversitesi, Adana; 2020.

8. Schmeling A, Geserick G, Reisinger W, Olze A. Age estimation. Forensic science international. 2007;165(2-3):178-81.

9. Greulich WW, Pyle SI. Radiographic atlas of skeletal development of the hand and wrist: Stanford university press; 1959.

10. Gilsanz V, Ratib $O$. Hand bone age: a digital atlas of skeletal maturity: Springer Science \& Business Media; 2005.

11. Yıldırım A, Çetin I, Erdal Ö, Gümüş B. Adli Tıp Anabilim Dalına 2006-2010 Yılları Arasında Yaş Tayini için Başvuran Olguların Değerlendirilmesi. Çağdaş Tıp Dergisi. 2011;1(2).

12. Baransel Isır A, Dülger H. 1998-2005 yılları arasında Gaziantep Üniversitesi Adli Tıp Anabilim Dalında raporlandırılan yaş tayini olgularının irdelenmesi. Türkiye Klinikleri Adli Tıp 
Dergisi. 2007;4(1):1-6.

13. Bilgin N, Çekin N, Gülmen M, Alper B. Çukurova Üniversitesi Tıp Fakültesi Adli Tıp Anabilim Dalı'na başvuran yaş tayini olgularının retrospektif değerlendirilmesi. Mersin Üniv Tıp Fak Dergisi. 2003;2:140-4.

14. Polat F. Türkiye'de öğrenim gören yabancı uyruklu ilköğretim öğrencilerinin karşılaştıkları sorunlar ve çözüm önerileri/Problems encountred by the foreign elementary school students who study in Turkey and sollution offers. 2012.

15. Tokyay M. Suriyeli kız çocukları Türkiye'de cinsel istismarın en büyük mağduru oldu: Artış yüzde 736. euronews. 26 Oct 2019.

16. Association R. Number of Syrians in Turkey October 2020. 15 Nov 2020.

17. Şimşek Ş, Fettahoğlu EÇ, Özatalay E. Cinsel istismara uğramış çocuklarda ve ebeveynlerinde travma sonrası stres bozukluğu. Dicle Tıp Dergisi. 2011;38(3):318-24.

18. Topal $Y$, Balcı Y, Erbaş M. Muğla'da 18 yaş ve altı cinsel istismar olgularının retrospektif değerlendirilmesi. Ortadoğu Tıp Dergisi. 2018;10(2):135-41.

19. UNICEF. Uprooted: The growing crisis for refugee and migrant children. 2016.

20. Ivanova $\mathrm{O}$, Rai $\mathrm{M}$, Kemigisha $\mathrm{E}$. A systematic review of sexual and reproductive health knowledge, experiences and access to services among refugee, migrant and displaced girls and young women in Africa. International journal of environmental research and public health. 2018;15(8):1583.

21. Iyakaremye I, Mukagatare C. Forced migration and sexual abuse: experience of Congolese adolescent girls in Kigeme refugee camp, Rwanda. Health Psychol Rep. 2016;4:261-71.

22. McGinn T, Austin J, Anfinson K, Amsalu R, Casey SE, Fadulalmula $\mathrm{SI}$, et al. Family planning in conflict: results of crosssectional baseline surveys in three African countries. Conflict and health. 2011;5(1):1-8.

23. Aile T, Aile SPB, Müdürlüğü THG. Suriyeliler ile Türkiye Cumhuriyeti Vatandaşları Arasındaki Evlilik iliş̧kileri Araştırması. 2016.

24. Yolcuoğlu iG. Türkiye'de çocuk koruma sisteminin genel olarak değerlendirilmesi. Sosyal Politika Çalışmaları Dergisi. 2009;18(18):43-58.

25. UNICEF. The State of the Worlds Children 2014 in Numbers: Revealing Disparities, Advancing Children's Rights: Every Child Counts. United Nations. 2014.

26. Şimsek Z, Kabalcıoğlu F, Kurcer M. Risk factors related with the complications on woman and their babies who delivered at Sanlıurfa Maternity Hospital. Journal of Health and Society. 2005;15(3):90-5.

27. Rehberi DÖBY. TC Sağlık Bakanlığı Ana Çocuk Sağlığı ve Aile Planlaması Genel Müdürlüğü. Ankara-2009 ss. 2000:9-41. 